\title{
Urinary bisphenol A concentrations in girls from rural and urban Egypt: a pilot study
}

Muna S Nahar ${ }^{1}$, Amr S Soliman²,3, Justin A Colacino ${ }^{1,3}$, Antonia M Calafat ${ }^{4}$, Kristen Battige ${ }^{1}$, Ahmed Hablas ${ }^{5}$, Ibrahim A Seifeldin ${ }^{5}$, Dana C Dolinoy ${ }^{1 *+}$ and Laura S Rozek ${ }^{1,3,6+}$

\begin{abstract}
Background: Exposure to endocrine active compounds, including bisphenol A (BPA), remains poorly characterized in developing countries despite the fact that behavioral practices related to westernization have the potential to influence exposure. BPA is a high production volume chemical that has been associated with metabolic dysfunction as well as behavioral and developmental effects in people, including children. In this pilot study, we evaluate BPA exposure and assess likely pathways of exposure among girls from urban and rural Egypt.

Methods: We measured urinary concentrations of total (free plus conjugated) species of BPA in spot samples in urban ( $N=30)$ and rural $(N=30)$ Egyptian girls, and compared these concentrations to preexisting data from agematched American girls ( $N=47$ ) from the U.S. National Health and Nutrition Examination Survey (NHANES). We also collected anthropometric and questionnaire data regarding food storage behaviors to assess potential routes of exposure.
\end{abstract}

Results: Urban and rural Egyptian girls exhibited similar concentrations of urinary total BPA, with median unadjusted values of 1.00 and $0.60 \mathrm{ng} / \mathrm{mL}$, respectively. Concentrations of urinary BPA in this group of Egyptian girls (median unadjusted: $0.70 \mathrm{ng} / \mathrm{mL}$ ) were significantly lower compared to age-matched American girls (median unadjusted: $2.60 \mathrm{ng} / \mathrm{mL}$ ) according to NHANES 2009-2010 data. Reported storage of food in plastic containers was a significant predictor of increasing concentrations of urinary BPA.

Conclusions: Despite the relatively low urinary BPA concentrations within this Egyptian cohort, the significant association between food storage behaviors and increasing urinary BPA concentration highlights the need to understand food and consumer product patterns that may be closing the gap between urban and rural lifestyles.

Keywords: Egypt, Urban, Rural, Bisphenol A

\section{Background}

Bisphenol A (BPA) is a monomer used in epoxy resins and polycarbonate plastic production. BPA is one of the highest volume chemicals with worldwide annual production of more than 8 billion pounds [1]. BPA continues to play a fundamental role in the plastics industry, given that BPA-based plastic materials have a variety of desirable properties including transparency, high impact strength, malleability, and superior adhesive properties [2]. BPA-based materials have a broad range

\footnotetext{
*Correspondence: ddolinoy@umich.edu

† Contributed equally

'Department of Environmental Health Sciences, School of Public Health,

University of Michigan, Ann Arbor, MI, USA

Full list of author information is available at the end of the article
}

of applications and are found in many commonly used products such as water bottles, dental sealants, medical equipment, epoxy resin linings in food and beverage cans, and thermal paper. Exposure is nearly ubiquitous in the general U.S. population, with over $92 \%$ of individuals sampled in the 2003-2004 National Health and Nutrition Examination Survey (NHANES) having detectable BPA levels in their urine [3]. BPA has the ability to leach from consumer products such as baby bottles, water bottles, polyvinyl chloride (PVC) tubing, and plastic containers, creating many opportunities for exposure [4-8]. Diet is an important route of BPA exposure due to its leaching from food and beverage containers [9-11]. Other important routes of exposures include inhalation from aerosolized BPA and dermal uptake
C Biomed Central 
from contact with thermal paper, medical or dental supplies [12-15].

There has been growing interest in BPA exposure given its presence and use in both developed and developing countries, as well as the health implications associated with its ability to mimic endogenous estrogen. BPA has a lower binding affinity, interacting with the $\alpha$ and $\beta$ estrogen receptors (ER) at $10^{4}$ times lower potency compared to estradiol [16]. However, BPA has been shown to stimulate rapid cellular responses at concentrations much lower than anticipated, potentially due to high binding affinities for G-protein coupled receptor 30 (GPR30) and estrogen related receptor gamma (ERR $\gamma)$ as seen in human studies $[17,18]$. BPA also antagonizes thyroid hormone and androgen function [16]. Both estrogenic and nonestrogenic effects from exposures to BPA in vivo and in vitro have been linked to changes in gene expression and cell proliferation in a variety of cells, tissues, and organs including the mammary glands and prostate $[19,20]$. Studies suggest that environmental exposure to BPA is associated with behavioral and reproductive abnormalities, as well as chronic diseases, especially when exposures occur during critical windows of development [21-25].

Exposure to endocrine disruptors varies within populations based on age, race, and sociodemographic factors $[3,26]$. Epidemiological studies conducted in Egypt also report geographical variance in disease incidence, highlighting the importance in evaluating the contribution of environmental exposures to these trends [27-29]. Developing countries, where there are major discrepancies in social and behavioral practices between urban and rural populations, offer a unique setting in which to study potential toxicant-disease interactions. Therefore, it is important to understand environmental exposure profiles in vulnerable populations, especially in developing countries where exposures remain largely uncharacterized. In this pilot study, we determined urinary concentrations of BPA in 60 premenstrual girls from urban and rural Egypt. BPA concentrations within the Egyptian cohort were compared to an age- and sex-matched United States population from NHANES 2009-2010. In addition, we investigated possible associations between urinary BPA concentrations and residential status, anthropometric measurements, and questionnaire data to assess potential sources of exposure.

\section{Methods}

\section{Subject selection}

In 2009, we recruited healthy females between the ages of 10-13 years living in either rural $(\mathrm{N}=30)$ or urban $(\mathrm{N}=30)$ areas of the Gharbiah province of Egypt, located 90 kilometers north of Cairo. Approximately $30 \%$ of Gharbiah's population resides in urban areas, with Tanta serving as the capital of all eight districts within the region. To determine rural versus urban status, participants were assigned a residence code based on their residential address that followed the Central Agency for Public Mobilization and Statistics (CAPMAS) national census coding of urban and rural areas [22]. To recruit urban subjects, we utilized a systematic random sampling of census records from Tanta. Rural subjects were recruited via systematic random sampling from two villages in two separate districts in the province. No refusals were encountered when selected subjects were approached in local primary schools to participate. All study participants were provided bus transportation to and from the Tanta Cancer Center and were not restricted from food and water access. Mothers of participants gave informed consent prior to sample collection. Approval from the Institutional Review Boards of the University of Michigan and the Gharbiah Cancer Society were obtained before starting the study. The involvement of the Centers for Disease Control and Prevention (CDC) laboratory was determined not to constitute engagement in human subject research.

\section{Urine sample collection and questionnaire}

Participants provided one spot urine sample, completed an administered questionnaire in Arabic, and were measured for height, weight, waist, and hip circumference. Urine samples from individuals were collected between 12:00 and 4:00 PM in sterile polypropylene containers between July and October 2009. Nine $\mathrm{mL}$ of urine were mixed thoroughly, split into two aliquots, and shipped on dry ice to the National Center for Environmental Health (NCEH) at the CDC for analysis and the University of Michigan School Of Public Health for archiving. An interviewer administered a lifestyle and diet questionnaire in Arabic in order to assess potential routes of exposure. The questionnaire, entitled "Comparison of Xenoestrogen Levels Among Prepubertal Females in Urban and Rural Gharbiah, Egypt," contained questions addressing residential history, personal care product usage, family history of cancer, use of canned foods, and food preparation and storage behaviors.

\section{Urinary BPA measurements}

The Division of Laboratory Sciences of NCEH, CDC determined the urinary concentrations of total (free plus conjugated forms) of BPA. Urine samples from each participant were subject to enzymatic hydrolysis of the conjugated (glucuronide and sulfate) BPA species and then automated cleanup. Total BPA was measured by on-line solid phase extraction coupled with isotope dilution-high performance liquid chromatography-atmospheric pressure chemical ionization-tandem mass spectrometry following a previously described analytical approach [30]. 
For quality assessment, in addition to the calibration standards, we analyzed two blanks, two low-concentration quality control (QC) materials $(\sim 2 \mathrm{ng} / \mathrm{mL}$ with individual measurements: 2.67 and $2.62 \mathrm{ng} / \mathrm{mL}$ ), and two high-concentration QCs $(\sim 9 \mathrm{ng} / \mathrm{mL}$ with individual measurements: 9.04 and $9.47 \mathrm{ng} / \mathrm{mL}$ ), along with the study samples. BPA was undetectable in the two blanks. Similar to measurements taken for NHANES, the limit of detection (LOD) at $0.4 \mathrm{ng} / \mathrm{mL}$ was determined using repeated measurements of low-level synthetic urine standards as previously described [30]. CDC personnel received coded specimens and did not have access to any personal, geographic, anthropometric, or questionnaire information from the study subjects.

\section{Statistical analysis}

Urinary BPA concentrations below the LOD were assigned a value of 0.28 , which was estimated by dividing the LOD by the square root of 2 . Both creatinine, measured using a colorimetric assay, and specific gravity, measured by refractometry, were recorded for each participants in the field. Given the high inter-individual variability and subjective assessment of creatinine, we adjusted urinary BPA concentrations for specific gravity (SG), previously used as a reliable alterative to creatinine $[31,32]$. Briefly, specific gravity adjusted urinary BPA concentrations were calculated by the formula $\mathrm{P}_{\mathrm{c}}=\mathrm{P}[(1.018$ - 1)/(SG-1)], where $P_{c}$ is the specific gravity adjusted BPA concentration $(\mathrm{ng} / \mathrm{mL}), \mathrm{P}$ is the measured unadjusted urinary BPA concentration, 1.018 is the sample population median specific gravity value, and SG is the measured specific gravity for each urine sample. Samples from three girls had specific gravity levels below 1.005; these samples were excluded from the analyses because they were too dilute, resulting in a final sample size for $\mathrm{BPA}$ analysis of $\mathrm{N}=57$. Age, body mass index (BMI), the use of plastic containers for food storage, and the consumption of canned foods were obtained from the questionnaire and anthropometric measurements. Urban and rural status was assigned as previously described [22]. Univariate statistics, including mean, geometric mean (GM), geometric standard error, median, and range for demographic, anthropometric, and BPA measurements were calculated. Chi-square tests were used to compare food storage behaviors and a $t$-test was used to compare urinary BPA concentrations between rural and urban girls. Pearson correlation analyses were conducted to assess the association between log-transformed unadjusted urinary BPA concentrations and individual covariates. Both specific gravity adjusted and unadjusted urinary BPA concentrations were reported in the univariate analyses, while log-transformed unadjusted BPA concentrations were used in the bivariate and multiple regression models to correct for departures from normality of the regression residuals. Specific gravity was included as a covariate in the multivariate analysis for each regression model. Age, BMI, and specific gravity were included in the multivariate regression model as continuous biologically relevant variables, while canned food consumption, food storage in plastics, and residential status were included as categorical variables. Canned food use and food storage in plastics were modeled as yes versus no in response to the questions "Do you eat tinned or canned food products?" and "Do you store food in plastic bags, containers, and/or Tupperware?", respectively. Regression coefficients with $p<0.05$ were considered statistically significant and $\beta$ values were interpreted by calculating percent change $\left[100\left(e^{\wedge} \beta-1\right)\right]$. Univariate and multiple regression analyses were conducted using the UNIVARIATE and REG procedures in SAS software (version 9.2, SAS Institute, Cary, NC).

We also performed statistical analysis of urinary BPA concentrations from 47 age- and sex-matched NHANES 2009-2010 participants using the SURVEYMEANS procedures in SAS with relevant strata, clusters, domain, and weights taking into account the complex sampling design. NHANES analysis was restricted to girls between the age of 10 and 13, who submitted urine samples during the afternoon session to match the sampling of our Egyptian cohort. A two-sample $t$-test was used to compare geometric means of urinary BPA measurements from NHANES to urinary BPA concentrations in our Egyptian subjects.

\section{Results}

Among the 60 girls recruited, three were excluded from analyses due to urine dilution (specific gravity $<1.005$ ) resulting in a final sample size for analysis of $\mathrm{N}=57$. Exclusion of these subjects from our analysis did not significantly alter the overall distribution of anthropometric and urinary BPA measurements from this cohort. Anthropometric parameters including BMI, hip circumference, and waist circumference were similar between the 28 urban and 29 rural Egyptian girls in this study (Table 1). Participants' age ranged from 10-13 years with an average age of 11 years for both urban and rural groups. Overall, there were no significant differences in age and anthropometric measurements between the two groups. When we compared anthropometric measurements to age and sex matched NHANES participants, American girls exhibited higher BMI and waist circumference compared to Egyptian girls.

Bivariate analyses of food storage behaviors indicate significantly different reports of canned food consumption but similar reports of food storage in plastics between urban and rural girls ( $p$-value $=0.001$ and 0.248 , respectively). Approximately $25 \%$ of girls residing in rural areas compared to $68 \%$ of those residing in urban areas 


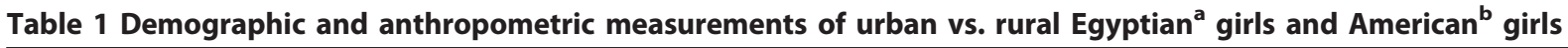

\begin{tabular}{|c|c|c|c|c|c|c|}
\hline & \multicolumn{2}{|c|}{ Urban Egyptians $(\mathrm{N}=28)$} & \multicolumn{2}{|c|}{ Rural Egyptians ( $N=29$ ) } & \multicolumn{2}{|c|}{ NHANES $(\mathrm{N}=47)$} \\
\hline & Mean, Median & Min, Max & Mean, Median & Min, Max & Mean, Median & Min, Max \\
\hline Age (years) & $11.4,11.4$ & $10.1,13.2$ & $11.6,11.6$ & $10.1,13.6$ & $11.3,11.0$ & $10.0,13.0$ \\
\hline $\begin{array}{l}\text { Body Mass Index } \\
\qquad\left(\mathrm{kg} / \mathrm{m}^{2}\right)\end{array}$ & $20.2,18.6$ & $13.8,30.2$ & $19.3,19.1$ & $13.7,31.2$ & $22.1,21.3$ & $14.5,34.2$ \\
\hline Hip Circumference (cm) & $62.0,60.6$ & $35.5,92.0$ & $59.9,59.3$ & $48.5,80.0$ & N/A, N/A & N/A, N/A \\
\hline $\begin{array}{l}\text { Waist Circumference } \\
(\mathrm{cm})\end{array}$ & $42.9,42.0$ & $31.0,62.0$ & $40.4,40.7$ & $33.0,56.3$ & $76.6,74.0$ & $55.2,111$ \\
\hline
\end{tabular}

${ }^{\mathrm{a} D e m o g r a p h i c ~ a n d ~ a n t h r o p o m e t r i c ~ m e a s u r e m e n t s ~ w e r e ~ s i m i l a r ~ b e f o r e ~ a n d ~ a f t e r ~ e x c l u s i o n ~ o f ~} 3$ girls who provided diluted urine specimens (specific gravity < 1.005; recruited $\mathrm{N}=60$, analyzed $\mathrm{N}=57$ )

${ }^{\mathrm{b}}$ Girls age 10-13 years from NHANES 2009-2010

reported consuming canned foods, while $69 \%$ of rural girls and $82 \%$ of urban girls reported storing food in plastic containers (Table 2). In general, $18 \%$ of rural girls and $61 \%$ of urban girls reported both canned food consumption and food storage in plastics within this population. Specific gravity was significantly lower among urban girls compared to rural girls ( $p=0.035$; data not shown).

The majority of girls (90\% rural and $68 \%$ urban) had detectable urinary BPA concentrations. Among the 57 study participants, both SG-adjusted and unadjusted urinary BPA measurements exhibited a right skewed non-normal distribution. Rural Egyptian girls had a median unadjusted urinary BPA concentration of $0.60 \mathrm{ng} / \mathrm{mL}$ (range $=<\mathrm{LOD}-12.0 \mathrm{ng} / \mathrm{mL}, \mathrm{GM}=0.89$ ), while urban Egyptian girls had a median unadjusted urinary BPA concentration of $1.00 \mathrm{ng} / \mathrm{mL}$ (range $=<$ LOD $-6.2 \mathrm{ng} / \mathrm{mL}, \mathrm{GM}$ $=0.79, p=0.478$, Table 3). After adjustment for specific gravity, median urinary BPA concentrations slightly increased to $1.08 \mathrm{ng} / \mathrm{mL}$ in rural girls and $1.02 \mathrm{ng} / \mathrm{mL}$ in urban girls $(p=0.578$, Table 3$)$. BPA urinary concentrations from an age- and sex-matched subset $(\mathrm{N}=47)$ from NHANES 2009-2010 were significantly higher than Egyptian $(\mathrm{N}=57)$ BPA measurements (GM: $1.96 \mathrm{ng} / \mathrm{mL}$ in NHANES, GM $=0.84 \mathrm{ng} / \mathrm{mL}$ in Egypt, $p<0.01$, Table 3).

No significant correlations were observed between unadjusted log-BPA urinary concentrations and individual covariates such as age, BMI, specific gravity, residential status, and canned food consumption (data not shown). However, a significant Pearsons correlation was detected between log-BPA concentrations and food storage in plastic containers $(p=0.041)$. Furthermore, multiple linear regression analysis was performed to assess the strength of association between BPA concentration and our primary predictor, residential status, after adjusting for well-known covariates. In the final model, we adjusted for urban/rural status, canned food consumption, food storage in plastic, specific gravity, age, and BMI (Table 4). The association between urinary BPA concentrations and residential status was not significant after adjusting for biological covariates $(\beta=$ -0.073 and $p=0.783$ ). Given the significant correlation between food storage in plastic containers and BPA in the bivariate analysis, we assessed the relationship between BPA concentrations and food storage behaviors after adjusting for covariates. Of the two food storage behaviors analyzed (Table 4), storage in plastic containers was a significant predictor of increasing urinary BPA concentration after adjusting for covariates $(\beta=0.626$ and $p=0.036$ ). Adjustment of this model, especially by canned food use, improved the association between urinary BPA and food storage in plastic. Girls who reported storage of food in plastic containers had, on average, $87 \%$ higher urinary BPA concentrations compared to girls who did not store food in plastic containers after adjusting for biological covariates, canned food use, and residential status.

\section{Discussion}

Total urinary BPA, including free and conjugated species, was detected at low parts-per-billion levels in premenstrual Egyptian girls, 21\% of whom exhibited concentrations below the limit of detection at $0.40 \mathrm{ng} / \mathrm{mL}$. Overall, the Egyptian cohort showed significantly lower urinary BPA concentrations compared to age- and sex-matched American girls from NHANES 2009-2010. Similar ranges of BPA concentrations compared to this Egyptian cohort

Table 2 Percent of urban vs. rural Egyptian girls who responded "Yes" to food storage behaviors

\begin{tabular}{lcccc}
\hline & Total (N = 57) & Urban (N = 28) & Rural $(\mathbf{N}=\mathbf{2 9}) \boldsymbol{p}$-value ${ }^{\mathbf{b}}$ \\
\hline Canned Food Use & $46 \%$ & $68 \%$ & $25 \%$ & $0.001^{*}$ \\
Food Storage in Plastic & $75 \%$ & $82 \%$ & $69 \%$ & 0.248 \\
Canned Food Use + Food Storage in Plastics & $39 \%$ & $61 \%$ & $18 \%$ & $0.001^{*}$ \\
\hline
\end{tabular}

${ }^{a}$ One non-respondent (rural $\mathrm{N}=28$, total $\mathrm{N}=56$ )

${ }^{\mathrm{b}}$ Two-sided significance calculated from Pearson chi-squared

*Significance at $p$-value $<0.05$ 
Table 3 Total urinary unadjusted and adjusted BPA concentrations ( $\mathrm{ng} / \mathrm{mL}$ ) in Egyptian girls compared to American ${ }^{\mathrm{a}}$ girls

\begin{tabular}{|c|c|c|c|c|c|c|c|}
\hline BPA & $\mathrm{N}$ & $\%$ Above LOD & Mean & Median & Min & Max & Geom.Mean (GSE') \\
\hline \multicolumn{8}{|l|}{ Unadjusted } \\
\hline All & 57 & 79 & 1.34 & 0.70 & $<\mathrm{LOD}$ & 12.0 & $0.84(0.10)$ \\
\hline Urban & 28 & 68 & 1.24 & 1.00 & $<\mathrm{LOD}$ & 6.20 & $0.79(0.14)$ \\
\hline Rural & 29 & 90 & 1.44 & 0.60 & $<\mathrm{LOD}$ & 12.0 & $0.89(0.89)$ \\
\hline NHANES $^{a}$ & 47 & 98 & 2.83 & 2.60 & $<\mathrm{LOD}$ & 16.1 & $1.96(0.23)^{*}$ \\
\hline \multicolumn{8}{|l|}{ Specific Gravity } \\
\hline \multicolumn{8}{|l|}{ Adjusted } \\
\hline All & 57 & & 1.75 & 1.02 & $<L O D$ & 10.8 & $1.00(0.14)$ \\
\hline Urban & 28 & & 2.13 & 1.02 & $<\mathrm{LOD}$ & 10.8 & $1.14(0.25)$ \\
\hline Rural & 29 & & 1.39 & 1.08 & $<\mathrm{LOD}$ & 8.64 & $0.89(0.16)$ \\
\hline
\end{tabular}

${ }^{\mathrm{a}}$ Girls age 10-13 years from NHANES 2009-2010

${ }^{\mathrm{b}} \mathrm{GSE}=$ Geometric standard error; LOD $=0.4 \mathrm{ng} / \mathrm{mL}$

* Geometric means significantly differed between NHANES and Egypt cohorts when tested using two sample $t$-test $(p<0.01)$

have been reported in several international cohorts. Recent studies report that the median concentration of urinary BPA in 48 Japanese women was $1.2 \mathrm{ng} / \mathrm{mL}$ [33], while the median BPA concentration of 60 pregnant Mexican women was $0.95 \mathrm{ng} / \mathrm{mL}$ [34] and 100 pregnant women in the Netherlands was $1.2 \mathrm{ng} / \mathrm{mL}$ [35]. Comparison of urinary BPA concentrations between countries may be confounded by the method of analysis, adjustment for urine dilution, timing of urine collection, as well as age, sex, and genetic differences [3,36,37]. However, differences can also be attributed to country specific lifestyle practices including food storage and consumer product use. Therefore, characterizing dietary and behavioral habits may provide insight into the potential exposure pathways and contribution of BPA to human health.

Previous studies have described heterogeneity in disease rates in Egypt based on urban/rural status. Women residing in urban Gharbiah Province of Egypt were found to have a 2-4 times higher incidence rate of

Table 4 Residential status, canned foods, and food storage in plastics as potential predictors of (log transformed) urinary BPA concentrations $(\mathrm{ng} / \mathrm{mL})$

\begin{tabular}{ccccc}
\hline & $\boldsymbol{\beta}$ & $\mathbf{9 5 \%} \mathbf{C l}$ & $\boldsymbol{p}$-value & \% change \\
\hline Residential Status $^{\mathrm{a}}$ & -0.072 & {$[-0.577,0.434]$} & 0.777 & $-6.95 \%$ \\
Residential Status $^{\mathrm{b}}$ & -0.073 & {$[-0.600,0.455]$} & 0.783 & $-7.04 \%$ \\
\hline Canned Food Use $^{\mathrm{a}}$ & 0.365 & {$[-0.118,0.848]$} & 0.136 & $44.05 \%$ \\
Canned Food Use $^{\mathrm{b}}$ & 0.394 & {$[-0.108,0.895]$} & 0.121 & $62.42 \%$ \\
\hline Food Storage in Plastic $^{\mathrm{a}}$ & 0.552 & {$[0.007,1.097]$} & $0.047^{*}$ & $73.67 \%$ \\
Food Storage in Plastic $^{\mathrm{b}}$ & 0.546 & {$[-0.012,1.105]$} & 0.055 & $72.63 \%$ \\
Food Storage in Plastic $^{\mathrm{c}}$ & 0.626 & {$[0.043,1.210]$} & $0.036^{*}$ & $87.01 \%$
\end{tabular}

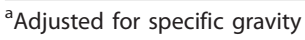

${ }^{\mathrm{b}}$ Adjusted for specific gravity, BMI, and age

${ }^{\mathrm{C}}$ Adjusted for all other covariates (specific gravity, BMI, age, residential status, plastic storage, and canned food)

*Significance at $p$-value $<0.05$; predictors were run separately for models $a, b$, and $c$ estrogen receptor positive breast cancer compared to their rural counterparts [29]. Xenoestrogen exposure during critical windows of development has been proposed to be a likely explanation for increasing cancer incidences, especially in regards to breast cancer [22,27,38-41]. In this pilot study, however, we did not identify differential exposure to BPA, estimated from the urinary concentrations of BPA, based on residential status in premenstrual Egyptian girls. Both average unadjusted and SG-adjusted BPA concentrations were in the low parts-per-billion range and did not significantly differ between the urban and rural cohorts. Instead, specific gravity differed between urban and rural girls, indicating an underlying variability in fluid consumption, individual health, and/or lifestyle factors within the two cohorts.

It is possible that these data represent cohort-specific xenoestrogen exposure in Egypt, as discrepancies in xenoestrogen exposures between urban and rural populations have previously been observed in several studies $[42,43]$. Lower BPA levels were found in sediments in rural compared to urban Okinawa, Japan, suggesting higher BPA exposure from industrial wastes and less so from agricultural activities [44]. Fu and colleagues traced BPA in atmospheric aerosols from urban, rural, marine, and polar regions around the world, and observed higher atmospheric BPA concentrations in urban regions especially in countries like India where open burning of plastic wastes are common practice [45]. Additionally, the preference of urban populations near Alexandria, Egypt for diets high in meat and fat may expose residents to higher levels of synthetic estrogens reported in poultry and meat [46].

These Egyptian girls, as with other populations around the world, are likely to have exposure to a complex mixture of xenobiotics. When we characterized exposure to phthalates within the same population, urban girls exhibited higher specific gravity adjusted urinary 
concentrations of several phthalate metabolites compared to rural residents, although these differences were not observed in unadjusted concentrations [47]. Characterization of multiple chemical exposures is necessary to understand the impact of the environment on disease, given that a combination of several low level exposures may contribute to a larger xenobiotic body burden and subsequently influence disease incidence $[48,49]$.

As occupational exposures are unlikely in girls of this age group, the most likely route of exposure is dietary ingestion of BPA [9-11,50]. Several studies show migration of BPA from PVC films in food packaging and cans into foodstuff especially at high temperatures [8,51-53]. Epoxy resin containing BPA is widely used to coat metal products such as canned foods and bottle tops [54]. In addition, some food and drink containers are composed of polycarbonate plastics $[9,10]$. Therefore, in our study we asked participants about food storage behaviors, and analyzed canned food consumption and food storage in plastic containers as predictors of urinary BPA concentrations. We found a significantly positive association between food storage in plastic containers and BPA concentrations after adjusting for urinary specific gravity, age, BMI, and residential status. A parallel study within this population noted that food storage in plastic was significantly associated with higher urinary phthalate metabolite concentrations [47], suggesting the use of both BPA-containing polycarbonate plastics as well as phthalate-containing PVC storage products by these Egyptian girls. Studies often report BPA exposure from canned food consumption to be relevant [55]; however, our results do not indicate a direct significantly positive association between canned food use and urinary BPA. Interestingly, canned food use improved the association between urinary BPA concentrations and food storage in plastics, acting as a potential confounder. Irrespective of these food consumption and storage behavior associations, BPA concentrations within this Egyptian cohort were significantly lower compared to age- and sex-matched US NHANES data. Comparatively low urinary concentrations of BPA among Egyptian girls may be attributed to the limited use of BPA containing products like thermal paper, and medical equipment, as well as relatively low frequency of plastic food storage and canned food consumption.

Although spot urine samples reflect recent BPA exposure, multiple spot urine testing is recommended for future studies in order to account for temporal variation in exposure $[31,56,57]$. Besides the small sample size and the collection of only one spot urine sample from each girl, a major limitation of this pilot study is the inclusion of only general behavioral questions. Instead, specific analyses of behavioral and dietary habits are required such as whether food stored in cans and plastics were heated or how many canned food or drink products were consumed. Characterization of the types of food stored and the frequency of use may also be necessary, given that Egyptian adults and children are exposed to different diets especially in rural Egypt [58] and that certain foods are more likely to leach BPA from containers [59].

To the best of our knowledge, this study is one of the first to assess food storage practices and urinary BPA concentrations in girls from a developing country. Many exposure assessment studies focus on developed countries; for example, a previous study found a median unadjusted BPA concentration of $1.8 \mathrm{ng} / \mathrm{mL}$ among 1,200 6-8 year old girls from three large US cities [60]. Exploring environmental exposures such as BPA at vulnerable stages of development, including the peripubertal period, will be important for assessing potential risks to disease later in life in developing countries. Reports on the Egyptian food market indicate an increased demand for packaged and convenience foods, and the canned food industry is expected to grow rapidly with the reduction of fresh produce [61]. According to the National Food Consumption Survey, an increasing number of Egyptian households reported consumption of ready-made foods and carbonated soft drinks, and substantial differences in food consumption patterns were observed between urban and rural households over several decades [62]. Given the expected expansion of the Egyptian economy, communities must be cognizant of the potential increase in various environmental exposures and consider appropriate actions to prevent potential adverse health outcomes in the future.

\section{Conclusions}

In this assessment of BPA in girls in the province of Gharbiah, Egypt, similar concentrations of total urinary BPA concentrations were found between girls residing in urban and rural Egypt. The significant association between food storage in plastics and BPA concentrations suggests that diet is an important route for BPA exposure in this population. A closer look at changing food patterns and the consumer market may provide a better understanding of BPA exposure in developing countries.

\section{Disclaimer}

The findings and conclusions in this report are those of the authors and do not necessarily represent the views of the Centers for Disease Control and Prevention.

\section{Abbreviations}

BMI: Body Mass Index; BPA: Bisphenol A; CAPMAS: Central Agency for Public Mobilization and Statistics; CDC: Centers for Disease Control and Prevention; ER: Estrogen Receptor; GM: Geometric Mean; LOD: Limit of Detection; NCEH: National Center for Environmental Health; NHANES: National Health and Nutritional Examination Survey; PVC: Polyvinyl Chloride; SG: Specific Gravity. 


\section{Acknowledgements}

This work was supported by the University of Michigan Cancer

Epidemiology Education in Special Populations Program (R25 CA112383), the University of Michigan NIEHS P30 Core Center (P30 ES017885), with generous support from the UM School of Public Health (SPH) and the SPH Department of Environmental Health Sciences. Support for DCD was provided by NIH grant ES017524, support for KB was provided by Training Grant CA112383, and support for MSN and JAC was provided by NIEHS Institutional Training Grant T32 ES007062. We acknowledge Xiaoyun Ye, Xiaoliu Zhou and Ryan Hennings for measuring the urinary concentrations of BPA and Stacy Endres at NIEHS for her effort in part of the data collection.

\section{Author details}

'Department of Environmental Health Sciences, School of Public Health, University of Michigan, Ann Arbor, MI, USA. ${ }^{2}$ Department of Epidemiology, School of Public Health, University of Michigan, Ann Arbor, MI, USA. ${ }^{3}$ Center for Global Health, University of Michigan, Ann Arbor, MI, USA. ${ }^{4}$ National Center for Environmental Health, Centers for Disease Control and Prevention, Atlanta, GA, USA. ${ }^{5}$ Tanta Cancer Center and the Gharbiah Cancer Society, Tanta, Egypt. ${ }^{6}$ Department of Otolaryngology, University of Michigan, Ann Arbor, MI, USA.

\section{Authors' contributions}

$A H, A S S, D C D, I A S$, and LSR conceived of this project and designed the study protocols. AH, ASS, and IAS supervised and conducted field collection, including subject recruitment. AMC was responsible for laboratory analysis of BPA. MSN and JAC performed statistical analysis. MSN, KB, DCD, and LSR drafted the manuscript, and all authors edited and approved the final draft of the manuscript.

\section{Competing interests}

The authors declare that they have no competing interests.

Received: 15 December 2011 Accepted: 2 April 2012

Published: 2 April 2012

\section{References}

1. Vandenberg LN, Chahoud I, Heindel JJ, Padmanabhan V, Paumgartten FJ, Schoenfelder G: Urinary, circulating, and tissue biomonitoring studies indicate widespread exposure to bisphenol A. Environ Health Perspect 2010, 118:1055-1070

2. Ben-Jonathan N, Steinmetz R: Xenoestrogens: the emerging story of bisphenol a. Trends Endocrinol Metab 1998, 9:124-128.

3. Calafat AM, Ye X, Wong LY, Reidy JA, Needham LL: Exposure of the U.S. population to bisphenol A and 4-tertiary-octylphenol: 2003-2004. Environ Health Perspect 2008, 116:39-44.

4. Mountfort KA, Kelly J, Jickells SM, Castle L: Investigations into the potential degradation of polycarbonate baby bottles during sterilization with consequent release of bisphenol A. Food Addit Contam 1997, 14:737-740.

5. Carwile JL, Luu HT, Bassett LS, Driscoll DA, Yuan C, Chang JY, Ye X, Calafat AM, Michels KB: Polycarbonate bottle use and urinary bisphenol A concentrations. Environ Health Perspect 2009, 117:1368-1372.

6. Sajiki J, Yonekubo J: Leaching of bisphenol A (BPA) from polycarbonate plastic to water containing amino acids and its degradation by radical oxygen species. Chemosphere 2004, 55:861-867.

7. Nerin C, Fernandez C, Domeno C, Salafranca J: Determination of potential migrants in polycarbonate containers used for microwave ovens by high-performance liquid chromatography with ultraviolet and fluorescence detection. J Agric Food Chem 2003, 51:5647-5653.

8. Lopez-Cervantes J, Paseiro-Losada P: Determination of bisphenol A in, and its migration from, PVC stretch film used for food packaging. Food Addit Contam 2003, 20:596-606

9. Kang JH, Kondo F, Katayama Y: Human exposure to bisphenol A. Toxicology 2006, 226:79-89.

10. Vandenberg LN, Hauser R, Marcus M, Olea N, Welshons WV: Human exposure to bisphenol A (BPA). Reprod Toxicol 2007, 24:139-177.

11. Joint FAO/WHO Expert Meeting to Review Toxicological and Health Aspects of Bisphenol A. Edited by: Safety F Ottawa 2010, 48

12. Biedermann S, Tschudin P, Grob K: Transfer of bisphenol A from thermal printer paper to the skin. Anal Bioanal Chem 2010, 398:571-576.
13. Calafat AM, Weuve J, Ye X, Jia LT, Hu H, Ringer S, Huttner K, Hauser R: Exposure to bisphenol $\mathrm{A}$ and other phenols in neonatal intensive care unit premature infants. Environ Health Perspect 2009, 117:639-644.

14. Fleisch AF, Sheffield PE, Chinn C, Edelstein BL, Landrigan PJ: Bisphenol A and related compounds in dental materials. Pediatrics 2010, 126:760-768

15. Vandentorren S, Zeman F, Morin L, Sarter H, Bidondo ML, Oleko A, Leridon $\mathrm{H}$ : Bisphenol-A and phthalates contamination of urine samples by catheters in the Elfe pilot study: implications for large-scale biomonitoring studies. Environ Res 2011, 111:761-764.

16. Welshons WV, Thayer KA, Judy BM, Taylor JA, Curran EM, vom Saal FS: Large effects from small exposures. I. Mechanisms for endocrinedisrupting chemicals with estrogenic activity. Environ Health Perspect 2003, 111:994-1006.

17. Thomas $P$, Dong J: Binding and activation of the seven-transmembrane estrogen receptor GPR30 by environmental estrogens: a potential novel mechanism of endocrine disruption. J Steroid Biochem Mol Biol 2006, 102:175-179

18. Matsushima A, Kakuta Y, Teramoto T, Koshiba T, Liu X, Okada H Tokunaga T, Kawabata S, Kimura M, Shimohigashi Y: Structural evidence for endocrine disruptor bisphenol A binding to human nuclear receptor ERR gamma. J Biochem 2007, 142:517-524

19. Richter CA, Birnbaum LS, Farabollini F, Newbold RR, Rubin BS, Talsness CE, Vandenbergh JG, Walser-Kuntz DR, vom Saal FS: In vivo effects of bisphenol A in laboratory rodent studies. Reprod Toxicol 2007, 24:199-224.

20. Wetherill YB, Akingbemi BT, Kanno J, McLachlan JA, Nadal A, Sonnenschein C, Watson CS, Zoeller RT, Belcher SM: In vitro molecular mechanisms of bisphenol A action. Reprod Toxicol 2007, 24:178-198.

21. Brody JG, Moysich KB, Humblet O, Attfield KR, Beehler GP, Rudel RA: Environmental pollutants and breast cancer: epidemiologic studies. Cancer 2007, 109:2667-2711.

22. Dey S, Zhang Z, Hablas A, Seifeldein IA, Ramadan M, El-Hamzawy H, Soliman AS: Geographic patterns of cancer in the population-based registry of Egypt: Possible links to environmental exposures. Cancer Epidemiol 2011, 35:254-264.

23. Lang IA, Galloway TS, Scarlett A, Henley WE, Depledge M, Wallace RB, Melzer D: Association of urinary bisphenol A concentration with medical disorders and laboratory abnormalities in adults. JAMA 2008, 300:1303-1310.

24. Braun JM, Kalkbrenner AE, Calafat AM, Yolton K, Ye X, Dietrich KN, Lanphear BP: Impact of early-life bisphenol a exposure on behavior and executive function in children. Pediatrics 2011, 128:873-882.

25. Meeker JD, Yang T, Ye X, Calafat AM, Hauser R: Urinary concentrations of parabens and serum hormone levels, semen quality parameters, and sperm DNA damage. Environ Health Perspect 2011, 119:252-257.

26. Diamanti-Kandarakis E, Bourguignon JP, Giudice LC, Hauser R, Prins GS, Soto AM, Zoeller RT, Gore AC: Endocrine-disrupting chemicals: an Endocrine Society scientific statement. Endocr Rev 2009, 30:293-342.

27. Dey S, Soliman AS, Merajver SD: Xenoestrogens may be the cause of high and increasing rates of hormone receptor positive breast cancer in the world. Med Hypotheses 2009, 72:652-656.

28. Dey S, Zhang Z, Hablas A, Seifeldein IA, Ramadan M, El-Hamzawy H, Soliman AS: Geographic patterns of cancer in the population-based registry of Egypt: Possible links to environmental exposures. Cancer Epidemiol 2011, 35:254-264

29. Dey S, Soliman AS, Hablas A, Seifeldein IA, Ismail K, Ramadan M, ElHamzawy H, Wilson ML, Banerjee M, Boffetta P, Harford J, Merajver SD: Urban-rural differences in breast cancer incidence in Egypt (1999-2006). Breast 2010, 19:417-423.

30. Ye X, Kuklenyik Z, Needham LL, Calafat AM: Automated on-line columnswitching HPLC-MS/MS method with peak focusing for the determination of nine environmental phenols in urine. Anal Chem 2005, 77:5407-5413.

31. Mahalingaiah S, Meeker JD, Pearson KR, Calafat AM, Ye X, Petrozza J, Hauser R: Temporal variability and predictors of urinary bisphenol A concentrations in men and women. Environ Health Perspect 2008, 116:173-178.

32. Miller RC, Brindle E, Holman DJ, Shofer J, Klein NA, Soules MR, O'Connor KA: Comparison of specific gravity and creatinine for normalizing urinary reproductive hormone concentrations. Clin Chem 2004, 50:924-932.

33. Ouchi $K$, Watanabe $\mathrm{S}$ : Measurement of bisphenol $\mathrm{A}$ in human urine using liquid chromatography with multi-channel coulometric electrochemical detection. J Chromatogr B Analyt Technol Biomed Life Sci 2002, 780:365-370. 
34. Cantonwine D, Meeker JD, Hu H, Sanchez BN, Lamadrid-Figueroa $\mathrm{H}$, Mercado-Garcia A, Fortenberry GZ, Calafat AM, Tellez-Rojo MM: Bisphenol a exposure in Mexico City and risk of prematurity: a pilot nested case control study. Environ Health 2010, 9:62.

35. Ye X, Pierik FH, Hauser R, Duty S, Angerer J, Park MM, Burdorf A, Hofman A, Jaddoe WW, Mackenbach JP, Steegers EA, Tiemeier H, Longnecker MP: Urinary metabolite concentrations of organophosphorous pesticides, bisphenol A, and phthalates among pregnant women in Rotterdam, the Netherlands: the Generation R study. Environ Res 2008, 108:260-267.

36. Yang M, Kim SY, Lee SM, Chang SS, Kawamoto T, Jang JY, Ahn YO: Biological monitoring of bisphenol a in a Korean population. Arch Environ Contam Toxicol 2003, 44:546-551.

37. Volkel W, Bittner N, Dekant W: Quantitation of bisphenol A and bisphenol A glucuronide in biological samples by high performance liquid chromatography-tandem mass spectrometry. Drug Metab Dispos 2005 33:1748-1757.

38. Ibarluzea Jm J, Fernandez MF, Santa-Marina L, Olea-Serrano MF, Rivas AM, Aurrekoetxea JJ, Exposito J, Lorenzo M, Torne P, Villalobos M, Pedraza V, Sasco AJ, Olea N: Breast cancer risk and the combined effect of environmental estrogens. Cancer Causes Control 2004, 15:591-600.

39. Fernandez SV, Russo J: Estrogen and xenoestrogens in breast cancer. Toxicol Pathol 2010, 38:110-122.

40. Tokunaga M, Land CE, Tokuoka S, Nishimori I, Soda M, Akiba S: Incidence of female breast cancer among atomic bomb survivors, 1950-1985. Radiat Res 1994, 138:209-223.

41. Cohn BA, Wolff MS, Cirillo PM, Sholtz RI: DDT and breast cancer in young women: new data on the significance of age at exposure. Environ Health Perspect 2007, 115:1406-1414.

42. Rozati R, Reddy PP, Reddanna P, Mujtaba R: Role of environmental estrogens in the deterioration of male factor fertility. Fertil Steril 2002, 78:1187-1194.

43. Cruz S, Lino C, Silveira Ml: Evaluation of organochlorine pesticide residues in human serum from an urban and two rural populations in Portugal. Sci Total Environ 2003, 317:23-35

44. Kitada Y, Kawahata H, Suzuki A, Oomori T: Distribution of pesticides and bisphenol $A$ in sediments collected from rivers adjacent to coral reefs. Chemosphere 2008, 71:2082-2090.

45. Fu P, Kawamura K: Ubiquity of bisphenol $A$ in the atmosphere. Environ Pollut 2010, 158:3138-3143.

46. Sadek IA: Survey of hormonal levels in meat and poultry sold in Alexandria. Egypt. East Mediterr Health J 1998, 4:239.

47. Colacino JA, Soliman AS, Calafat AM, Nahar MS, Van Zomeren-Dohm A, Hablas A, Seifeldin IA, Rozek LS, Dolinoy DC: Exposure to phthalates among premenstrual girls from rural and urban Gharbiah. Egypt: A pilot exposure assessment study. Environ Health 2011, 10:40.

48. Darbre PD, Charles AK: Environmental oestrogens and breast cancer: evidence for combined involvement of dietary, household and cosmetic xenoestrogens. Anticancer Res 2010, 30:815-827.

49. Kortenkamp A: Breast cancer, oestrogens and environmental pollutants: a re-evaluation from a mixture perspective. Int J Androl 2006, 29:193-198.

50. Morgan MK, Jones PA, Calafat AM, Ye X, Croghan CW, Chuang JC, Wilson NK, Clifton MS, Figueroa Z, Sheldon LS: Assessing the Quantitative Relationships between Preschool Children's Exposures to Bisphenol A by Route and Urinary Biomonitoring. Environ Sci Technol 2011, 45:5309-5316.

51. Munguia-Lopez EM, Gerardo-Lugo S, Peralta E, Bolumen S, Soto-Valdez H: Migration of bisphenol A (BPA) from can coatings into a fatty-food simulant and tuna fish. Food Addit Contam 2005, 22:892-898.

52. Munguia-Lopez EM, Soto-Valdez $\mathrm{H}$ : Effect of heat processing and storage time on migration of bisphenol A (BPA) and bisphenol A-diglycidyl ether (BADGE) to aqueous food simulant from Mexican can coatings. J Agric Food Chem 2001, 49:3666-3671.

53. Guart A, Bono-Blay F, Borrell A, Lacorte S: Migration of plasticizersphthalates, bisphenol $A$ and alkylphenols from plastic containers and evaluation of risk. Food Addit Contam Part A Chem Anal Control Expo Risk Assess 2011, 28:676-685.

54. Kang $\mathrm{JH}$, Kito $\mathrm{K}$, Kondo F: Factors influencing the migration of bisphenol A from cans. J Food Prot 2003, 66:1444-1447.

55. Carwile JL, Ye X, Zhou X, Calafat AM, Michels KB: Canned soup consumption and urinary bisphenol $\mathrm{A}$ : a randomized crossover trial. JAMA 2011, 306:2218-2220.
56. Teitelbaum SL, Britton JA, Calafat AM, Ye X, Silva MJ, Reidy JA, Galvez MP, Brenner BL, Wolff MS: Temporal variability in urinary concentrations of phthalate metabolites, phytoestrogens and phenols among minority children in the United States. Environ Res 2008, 106:257-269.

57. Ye X, Wong LY, Bishop AM, Calafat AM: Variability of urinary concentrations of bisphenol $A$ in spot samples, first morning voids, and 24-hour collections. Environ Health Perspect 2011, 119:983-988.

58. Sukkary-Stolba S: Food classifications and the diets of young children in rural Egypt. Soc Sci Med 1987, 25:401-404.

59. Noonan GO, Ackerman LK, Begley TH: Concentration of bisphenol A in highly consumed canned foods on the U.S. market. J Agric Food Chem 2011, 59:7178-7185.

60. Wolff MS, Teitelbaum SL, Pinney SM, Windham G, Liao L, Biro F, Kushi LH, Erdmann C, Hiatt RA, Rybak ME, Calafat AM: Investigation of relationships between urinary biomarkers of phytoestrogens, phthalates, and phenols and pubertal stages in girls. Environ Health Perspect 2010, 118:1039-1046.

61. Abdel-Aziz H: Egypt: An overview of the food market Service USC. Alexandria, Egypt: U.S Commercial Service in Alexandria, Egypt.; 2008, 3.

62. Galal OM: The nutrition transition in Egypt: obesity, undernutrition and the food consumption context. Public Health Nutr 2002, 5:141-148.

\section{doi:10.1186/1476-069X-11-20}

Cite this article as: Nahar et al:: Urinary bisphenol A concentrations in girls from rural and urban Egypt: a pilot study. Environmental Health 2012 11:20

\section{Submit your next manuscript to BioMed Central and take full advantage of:}

- Convenient online submission

- Thorough peer review

- No space constraints or color figure charges

- Immediate publication on acceptance

- Inclusion in PubMed, CAS, Scopus and Google Scholar

- Research which is freely available for redistribution

Submit your manuscript at www.biomedcentral.com/submit
C) Biomed Central 